\title{
Decision processes of a suicide bomber - integrating economics and psychology
}

\section{Working Paper}

\section{Author(s):}

Pittel, Karen; Rübbelke, Dirk T.G.

Publication date:

2009-02

Permanent link:

https://doi.org/10.3929/ethz-a-005763982

Rights / license:

In Copyright - Non-Commercial Use Permitted

Originally published in:

Economics Working Paper Series 09/106 


\title{
CER-ETH - Center of Economic Research at ETH Zurich
}

\section{Decision Processes of a Suicide Bomber - Integrating Economics and Psychology}

\author{
Karen Pittel and Dirk T.G. Rübbelke
}

Working Paper 09/106

February 2009

\section{Economics Working Paper Series}

\section{EH}

Eidgenössische Technische Hochschule Zürich Swiss Federal Institute of Technology Zurich 


\title{
Decision Processes of a Suicide Bomber - Integrating Economics and Psychology
}

\author{
Karen Pittel* and Dirk T.G. Rübbelke ${ }^{\dagger}$
}

February 2009

\begin{abstract}
This paper provides a theoretical analysis regarding the rationality of suicide attacks from an economist's point of view. It is argued that although a terrorist gives up future utility from consumption by committing a suicide attack, this loss can be overcompensated by the utility he derives from the attack. Some individual cases of suicide bombers are presented in order to elucidate the diversity of motivations behind the attacks.

We derive conditions under which a rational agent might decide to become a suicide bomber - or to announce the attack and defect later. The paper shows why the decision to commit a suicide attack can be time-inconsistent and what mechanisms might prevent time-inconsistency. Integrating the psychological concepts of cognitive dissonance and terror management theory into our economic analysis, we demonstrate why - although predicted by standard economic theory - defection is a phenomenon rarely observed.

We finally present some policy implications. In the light of our analysis, policies that focus on material well-being seem less promising than policies that address non-monetary benefits of suicide attacks. The paper concentrates on two policy strategies: offering alternatives with respect to the aims of terrorism as well as the means to attain them - and reducing the information bias - with respect to the availability as well as the access to information.
\end{abstract}

Keywords: terrorism, discounting, rationality, time-consistency

JEL classification: D74, D69

${ }^{*}$ CER - Center of Economic Research, ZUE F12, ETH Zentrum, 8092 Zurich, Switzerland, email: kpittel@ethz.ch

${ }^{\dagger}$ CICERO, Pb. 1129 Blindern, 0318 Oslo, Norway, email: dirk.ruebbelke@cicero.uio.no 


\section{Introduction}

Suicide attacks seem to be - at first glance - a puzzling phenomenon for economists. When it is assumed that an individual maximizes his intertemporal utility, how can it be optimal to forego a large part of his future utility?

Several theories have been put forward to explain suicide missions or, more generally, terrorist acts. Among these explanations, psychopathy and hate rank high in the public opinion. Yet, research suggests that most terrorists are not driven by either of these causes (Silke 1998, Weatherston/Moran 2003), but are rather attracted by the feeling of purpose and belongingness to some peer group as well as common socio-political goals and the desire for immortality (see Maikovich 2005, Routledge/Arndt 2008). In this paper we show that, although often stigmatized as irrational, suicide attacks can be compatible with the actions of a rational, welfare maximizing agent.

Our interest in this specific type of terrorism is well justified by empirical data: Although suicide attacks made up only $3 \%$ of all terrorist incidents in the period from 1980 to 2001, they were responsible for $48 \%$ of all related deaths (see Pape 2003). The phenomenon of people being willing to sacrifice their life for some 'higher goal' is, however, neither new nor confined to specific religions, cultures or political convictions. From the ancient Jewish Zealots in 73 AD, over the 11th-12th century Ismaili Assassins (see Rapoport 1984, Pape 2005) to the almost 5000 Japanese 'kamikaze' pilots in World War II (Laquer 1990), political or religiously motivated

suicide has been a recurrent phenomenon. Also, starting early in history, people willing to sacrifice themselves have been used systematically as weapons. Especially the last two decades have witnessed a dramatic increase in suicide attacks in countries as diverse as Lebanon, India, Chechnya and the US (Pape 2003). Impacts may be immense as, e.g., the attack on the World Trade Center alone killed almost 2800 people. The puzzling question is why people are willing to go to this extreme.

By committing a suicide attack, an individual foregoes the utility from consumption subsequent to his premature death, yet he might derive additional utility from other, altruism related factors, such as from having abetted the aims of a peer group which could be, e.g., his people or denomination, possibly represented by a terrorist organization. Also the status and even material well-being of the terrorist's remaining family might increase due to his sacrifice. Terrorist organizations foster immaterial rewards by tying the potential attacker as close as possible to the group. Organizations like Hamas and IRA, e.g., provided public goods like health services and social welfare (see Hilsenrath 2005, Bueno de Mesquita 2005), education (CFR 2009) or police services (see Silke 1999). This way, the agent's identification with the organization and its goals increases and the organization's utility gains more and more weight for his own welfare 
(see also Pittel/Rübbelke 2006). Beyond that, the agent might expect that the attack will turn him into a martyr who is reverently commemorated by his peer group and family, thus awarding him either religious or symbolic immortality (Routledge/Arndt 2008). Committing to an attack might even raise his social status before the attack and induce anticipatory feelings of pride and accomplishment. Last but not least, an agent who is driven by religious motives might expect to be rewarded posthumously by some higher authority.

In contrast to utility from individual consumption, the utility derived from altruistic motives and an increase in social status might carry weight with the agent even if they arise only after his death. Taking all the above factors into consideration, it can indeed be rational for a person to become a suicide bomber. In this case, the intertemporal utility of his shortened life exceeds the utility from a life lived to its natural end.

Using the mechanisms described, terrorist organizations try to persuade individuals to become suicide bombers. Governments on the other hand use the same means in order to dissuade potential assassins. By threatening, e.g., to retaliate against a bomber's family, they aim at creating negative utility effects that outweigh the positive effects created in the bomber's environment. ${ }^{1}$ We will shortly discuss this and other policy options at the end of this paper.

We also deal with the question whether not only commitment to a suicide attack can be rational but also defection at a later state. Examples for this seemingly irrational and timeinconsistent behavior have been reported even recently. ${ }^{2}$ We show that this type of behavior is also compatible with standard economic theory and rational agents. 'Chickening out' can be a time-consistent course of action from the perspective of the individual terrorist. In this case, the agent maximizes his utility by first announcing to commit the attack, although he does not plan to carry it out. In this case, the actions of the terrorist might seem to be time-inconsistent to an outsider but do not have to be from the terrorists' perspective.

Whether or not committing to an attack can indeed be time-inconsistent, depends on the way the terrorist discounts the future. We compare two different types of discounting. First we assume constant discount rates as mostly done in economic theory. Yet, although this assumption is fairly common, it has often been found empirically that individuals' discount rates are not constant over time. Rather, discounting seems to follow a hyperbolic path where payoffs which are closer in time are discounted at a higher rate than payoffs in the distant future (see e.g. Ainslie/Haslam 1992). ${ }^{3}$

The paper shows that time-inconsistent behavior cannot arise if discount rates are constant.

\footnotetext{
${ }^{1}$ Whether threats and retaliation constitute an efficient way to combat suicide attacks is analyzed, e.g., by Lee/Sandler (1989).

${ }^{2}$ Decisions are called time-inconsistent if an agent favors a specific payoff at time $t_{0}$, but this payoff is not optimal anymore when reevaluated at some point in the future.

${ }^{3}$ For these and other discounting related issues, see e.g. Loewenstein/Elster (1992).
} 
If however discounting is hyperbolic, time-inconsistency is conceivable. In this case an agent perceives a future suicide mission to be utility maximizing from today's perspective, yet not when reconsidered at the time of the attack.

Following the results of the above analysis one could expect that potential suicide bombers who rescind their decision are not too uncommon. That evidence of this kind of behavior is rather scarce may of course be due to limited access to this type of information. Nevertheless, it is also conceivable that the time-inconsistency of decisions can be overcome by psychological processes. We show that a terrorist's reactions to cognitive dissonance and mortality salience might provide explanations as to why the decision to carry out a suicide attack is more often than not put into practise.

Cognitive dissonance arises from decisions that are associated with positive as well as negative aspects for an individual - as obviously the case for terrorism. It creates a tension that an individual tries to reduce or eliminate by manipulating his perception of reality. As a result costs and benefits of becoming a suicide bomber are perceived differently which might affect an agent's decision to carry out an attack. Similarly, experiments showed that an increased mortality salience intensifies people's need for cultural identity and decreases their tolerance towards other cultures. The readiness to defend their view of the world against others increases, thereby paving the way for terrorism. We show that cognitive dissonance as well as mortality salience might prevent time-inconsistent decisions.

The paper proceeds as follows: Section 2 illustrates different profiles and motivations of terrorists using specific examples. The decision problem of a rational individual who ponders to become a suicide bomber is then analyzed in Section 3 for the standard case of constant discount rates. After a short discussion of the time-consistency of decisions in this scenario, Section 4 introduces the concept of hyperbolic discounting and analyzes its implications. Section 5 argues that the theoretical results of the previous sections and the empirics on rescinded suicide attacks might be at odds. The section demonstrates how external influences on the terrorist as well as internal manipulation mechanisms that result from cognitive dissonance and mortality salience can reconcile theory and empirics. Section 6 gives some policy implications and Section 7 concludes.

\section{Suicide attackers - diverse profiles and motivations}

Profiles of suicide attackers are very diverse as terrorists come from a variety of social, political and religious backgrounds. Nevertheless, it seems possible to classify their motivation according to the effects that arise for them from the attack. In the following we distinguish between three main categories: 
- posthumous effects: rise in the social and monetary status of the attackers family; immortality of the attacker; accomplishment of political, religious and social goals.

- announcement effects: admiration and rise in status of the attacker before the attack.

- defection effects: negative consequences arising in case the attacker does not carry out the attack.

Not all of these motivations can be found for every attacker, yet some elements can almost always be identified. In the following we provide some examples.

Let us consider the cases of two female attackers first. According to Schweitzer (2006: 8), in the period between 1985 and 2006 nearly 15 percent of the overall number of actual suicide bombers around the world were female, although among some groups, e.g. Chechen rebels and the Kurdistan Workers Party, women form a majority of the attackers (see Pape 2005). ${ }^{4}$ The following examples show that background and motivation of female attackers are as diverse as those of their male counterparts, yet they also show how difficult and complex it can be to verify what is driving a suicide bomber.

Wafa Idris, a 28-year-old Palestinian, detonated a bomb in a suicide attack in central Jerusalem in January 2002, killing an Israeli and injuring dozens others. She was the first female suicide bomber in the Israeli-Palestinian conflict. Victor (2003) describes her as "a talented young woman, married and divorced because she was sterile" (Victor 2003: 39). After her divorce she "was desperate because she knew perfectly well there was no future for her in any aspect of the Palestinian society" (Alvanou 2007: 75). It seems that due to her despair, committing the attack was the only hope she had to escape her living conditions and to restore her reputation, ${ }^{5}$ although Idris' mother claimed that her daughter's attack was not due to desperation (see Bennet 2002). As religious motives probably did not play a major role in her decision - she was reported to be not particularly religious - a nationalist fervor may also have contributed as an important impetus. Aksa Martyrs Brigades pointed to this possible motive by stating that she died in the name of Palestine and anecdotal evidence supporting this conclusion might be found in her social and family background: besides being an activist of the Fatah faction, she was directly afflicted by the Palestinian-Israeli conflict as she was a resident of the Amari refugee camp and worked as a volunteer medic with an affiliate of the International Red Cross that was medicating Palestinians among which were people wounded by Israeli soldiers.

The second female example, 22-year-old Dareen Abu Aysheh, a senior student of English Literature, detonated a bomb at an Israeli roadblock in West Ramallah and wounded four Israelis in February 2002. She left a videotape in which she explicitly expressed that she was

\footnotetext{
${ }^{4}$ With 67 incidents, Israel and Palestinian territories are those areas second most targeted by female suicide bombers, while Sri Lanka ranks first with a number of 75 (Schweitzer 2006: 8).

${ }^{5}$ Ordinary suicide, i.e. suicide caused by personal distress, is expressly forbidden in Islam (Alvanou 2007: 38).
} 
following Idris' footsteps. She was an active supporter of the Hamas and, like Idris, affected by the killing of Palestinians by Israeli soldiers (Greenberg 2002).

In contrast to Idris, her motivation for the attack was probably influenced by religious considerations as she has been described as a religious person (Saloul 2003: 22). The role of her family is ambiguous. On the one hand, she was not the only suicide attacker in her family as a 17-year-old cousin also conducted a suicide bombing. On the other hand, her father stressed that her action was against the will of the family. Her brother, however, stated that "[s]he was sure that we would be killed for nothing, maybe at a roadblock or when our houses are bombed, and she used to say that it is better to die for a reason" (Greenberg 2002). So, desperation may also have been part of her motivation.

The examples of Idris and Abu Aysheh show that posthumous effects seem to play a major role in decisions to become suicide bombers. Yet, the composition of these effects differs. While Idris' motives seem to have been of a political and personal nature, i.e. abetting the Palestinian cause and restoring her reputation, Abu Aysheh's motivation was additionally influenced by religion. The expectation that the attack would be positively regarded by their families and increase their families' status, could have played a role, although at least Abu Aysheh's father's statement does not seem to support this.

Although not directly confirmable in the above cases, the hope to attain religious or symbolic immortality also seems to be a motivation for suicide bombers (see Routledge/Arndt 2008 and also Section 5.2). A specific example for heavenly rewards which has become notorious among the western media is the case of 16-year-old Hussam Bilal Abdu from Nablus. He was detained in 2004 while wearing an explosive belt and reported that the Popular Front for the Liberation of Palestine promised him 70 virgins in heaven if he carried out the suicide attack (Harel/Regular 2004).

Monetary incentives for suicide attackers and their family have repeatedly been reported from the Middle East but also other regions. Keller (2002), e.g., reports that in March 2002 the Iraq announced a payment of $\$ 25,000$ to families of suicide bombers in the West Bank and Gaza Strip (see also Krueger/Maleckova 2003). Hassan (2001) who interviewed numerous Palestinian militants affirms that the sponsoring organization usually gave between $\$ 3,000$ and $\$ 5,000$ to the bombers' families. In 2008, Amir Qasab, one of the gunmen who attacked several targets in Mumbai in a suicide mission, testified that the terrorist organization Lashkar-e-Taibat promised his father a $£ 2,000$ payment that could be used to run the family (McElroy 2008). ${ }^{6}$ Qasab ultimately refused to sacrifice himself and reported that he now feared the worst for his family

\footnotetext{
${ }^{6}$ Whether payments to the family should in general be viewed as an additional incentive, thus inducing positive utility to the suicide bomber, or only lessen the guilt associated with abandoning one's family, i.e. reducing the negative utility components of an attack, remains open to discussion, see e.g. Caplan (2006). For the subsequent analysis, this differentiation is, however, insubstantial as both lower the threshold to commit a suicide attack.
} 
as he was instructed he should not return alive at any cost. Qasab's case therefore also provides an example for the negative effects of defecting, i.e. for ways in which threats against the attacker and his family can be used by terrorist organizations to keep terrorists in line. Another example for this kind of deterring strategy is given by Berman/Laitin (2005) according to whom the Tamil Tigers "used intimidation for recruitment, threatening Tamils that they would punish relatives if they did not perform patriotic services" (Berman/Laitin 2005: 25).

In the following, we use the three types of motivation introduced and exemplified in this section to show when and under what circumstances, the decision to commit a suicide attack might be rational for an individual. ${ }^{7}$

\section{Optimal decisions under constant discounting}

\subsection{Decision rules}

Consider an agent who is offered the opportunity to commit a suicide attack at some future date $\bar{t}^{8}$ The agent can choose between three different courses of action that result in different present values of utility. First, he can decide not to become a suicide bomber. Second, he can agree to commit a suicide attack and indeed carry it out. Third, he can agree to commit the attack, but defect before carrying it out. An agent who maximizes intertemporal utility will choose the course of action that entails the highest present value of utility.

In case the agent decides against the attack, he derives utility from individual consumption $C_{t}$ only. Assuming his life expectancy to be $T$, the intertemporal utility $V$ from this decision is given by

$$
V_{0}^{T}\left(C_{t}\right)=\sum_{0}^{T} \rho^{t} U\left(C_{t}\right)
$$

where $\rho$ denotes a constant discount factor..$^{9}$

In case the agent decides to become a suicide bomber, he will carry out the attack after a planning and preparation period at time $\bar{t}$. In this case he is only able to consume until the time of the attack $\bar{t}$, i.e.

$$
V_{0}^{\bar{t}}\left(C_{t}\right)=\sum_{0}^{\bar{t}} \rho^{t} U\left(C_{t}\right) .
$$

\footnotetext{
${ }^{7}$ Please note that the concept of rationality we apply follows Wintrobe (2006) who postulates "rationality just means that, whatever the goal, a person chooses the best means to achieve it" (Wintrobe 2006: 170). For a more comprehensive treatment of rationality concepts and terrorism, see e.g. Caplan (2006).

${ }^{8}$ For simplicity we assume that the date of the attack cannot be chosen by the agent but is set exogenously. Also, the terrorist activity level is not modeled as a continuous variable with the maximum level being a suicide attack (see e.g. Azam 2005). We solely consider the decision to become or not to become a suicide bomber, i.e. a zero-one decision.

${ }^{9}$ The discount factor is given by $\rho=\frac{1}{1+\bar{\rho}}$ where $\bar{\rho}$ denotes the discount rate.
} 
Obviously, $V_{0}^{\bar{t}}<V_{0}^{T}$ holds if $\bar{t}<T$, such that it would never be rational for the agent to commit a suicide attack if no additional utility were derived from the attack. As already outlined above, we assume however that the agent not only derives utility from his own consumption, but also from his present as well as posthumous status in society, the well-being and status of his family and also from achieving the goals of his peer group. ${ }^{10}$ Taking these effects into account, (2) modifies to

$$
V_{0}^{\infty}(C, A, P)=\sum_{0}^{\bar{t}} \rho^{t}\left(U\left(C_{t}\right)+U\left(A_{t}\right)\right)+\sum_{\bar{t}}^{\infty} \rho^{t} U\left(P_{t}\right)
$$

where $U\left(A_{t}\right)$ is the utility an agent derives from the gain in status that follows from the announcement to participate even before the attack is carried out (announcement effect). ${ }^{11} U\left(P_{t}\right)$ represents the aggregate posthumous benefits of his decision (post-attack effects) which include non-altruistic components such as pride from being commemorated as a martyr and 'heavenly rewards' as well as altruistic components, e.g. positive effects on the peer group's goals and the rise in family status (and potentially wealth). ${ }^{12}$ Altruistic components may also comprise negative utility effects if the terrorist cares to some extend about those killed in the attack or worries about the family he leaves behind. In case these negative effects are strong, they might even render the aggregate posthumous utility negative.

Finally, the agent might decide at $t_{0}$ not only to volunteer for the attack but also to defect later. In this case he benefits from the announcement effect but foregoes the posthumous benefits. Furthermore, he is likely to suffer from repercussions inflicted by the terrorist organization which might result in a loss of his and his family's social and economic status and possibly even their lives. The utility from such a defecting strategy is given by

$$
V_{0}^{D}(C, A, D)=\sum_{0}^{\bar{t}} \rho^{t}\left(U\left(C_{t}\right)+U\left(A_{t}\right)\right)+\sum_{\bar{t}}^{T} \rho^{t} U\left(C_{t}\right)-\sum_{\bar{t}}^{\infty} \rho^{t} U\left(D_{t}\right)
$$

where $U\left(D_{t}\right)$ comprises the effects from defection (defection effect).

The agent now compares the utility arising from each of the three alternatives. Comparing (1) and (3) shows that the agent commits to the mission if the announcement and post-attack

\footnotetext{
${ }^{10}$ For simplicity, we set these non-consumptive utility components to zero for the case that the agent does not engage in the attack. Yet, we admit that in some cases, this assumption might not reflect reality. Take Idris, the first female Palestinian suicide attacker (see Section 2), for example: Her utility without the attack might be reduced by a bad reputation - due to divorce and sterility - and the shame caused to her family. We could model these effects but refrain from doing so, as it would render the disposition more complicated without adding insight about the mechanisms at work. We will, however, come back to this issue in the policy section (Section $6)$.

${ }^{11}$ For simplicity we assume the consumption at each point in time, $C_{t}$, to be independent of the attack decision.

${ }^{12}$ Azam (2005) follows a similar reasoning by employing the dynastic family hypothesis and linking the terrorist to his descendants by some altruism parameter.
} 
effects outweigh foregone future consumption:

$$
V_{0}^{\infty}>V_{0}^{T} \quad \Leftrightarrow \quad \sum_{0}^{\bar{t}} \rho^{t} U\left(A_{t}\right)+\sum_{\bar{t}}^{\infty} \rho^{t} U\left(P_{t}\right)>\sum_{\bar{t}}^{T} \rho^{t} U\left(C_{t}\right)
$$

where it should be noted that even in absence of altruistic motives, a rational agent might decide to become a suicide bomber if announcement effect and non-altruistic posthumous effects are sufficiently large.

From the comparison of (3) and (4), we see that the agent honestly commits to a suicide attack rather than defects if

$$
V_{0}^{\infty}>V_{0}^{D} \quad \Leftrightarrow \quad \sum_{\bar{t}}^{T} \rho^{t} U\left(P_{t}\right)>\sum_{\bar{t}}^{\infty} \rho^{t} U\left(C_{t}\right)-\sum_{\bar{t}}^{\infty} \rho^{t} U\left(D_{t}\right),
$$

i.e. if the posthumous effects overcompensate the loss of utility from foregone consumption net of the defection effect. So, even if the agent feels strongly about the harm he going to cause $\left(U\left(P_{t}\right)<0\right)$, it might be optimal for him to carry out the attack given that the defection effects are aggravating enough. The announcement effect does not appear in (6) as the agent receives announcement benefits independent of whether he eventually commits the attack.

Finally, in case that the utility from not volunteering as well as the utility from defecting are larger than the utility from the attack $\left(V_{0}^{\infty}<V_{0}^{T}\right.$ and $\left.V_{0}^{\infty}<V_{0}^{D}\right)$, the agent has to assess whether defecting or not volunteering at all is the better choice. An agent decides in favor of defection if the announcement effect is larger than the utility lost due to defection:

$$
V_{0}^{D}>V_{0}^{T} \quad \Leftrightarrow \quad \sum_{0}^{\bar{t}} \rho^{t} U\left(A_{t}\right)>\sum_{\bar{t}}^{\infty} \rho^{t} U\left(D_{t}\right) .
$$

Summing up, it can be optimal for a rational agent to commit a suicide attack as well as to defect. Yet, as we will show in the next subsection, in case the terrorist defects at $\bar{t}$, he already decides to do so at $t_{0}$. The above analysis can not account for terrorists for whom committing the attack is optimal initially but later becomes suboptimal. This type of time-inconsistent behavior cannot be explained under constant discount rates.

\subsection{Time-consistency of the decision}

First consider the decision between commitment and defection, i.e. (3) and (4). (6) shows that this decision - regardless of the time of the decision - solely depends on benefits accruing at $t \geq \bar{t}$. Consequently, a decision which was made at $t_{0}$ will still be optimal at $t=\bar{t}$ and is therefore time-consistent.

In case an agent decides against any involvement in the attack, the question arises whether he might regret his decision later. Comparing (1) and (3) as well as (1) and (4), not participating 
will still be optimal if ${ }^{13}$

$$
\begin{aligned}
& V_{\bar{t}}^{T}>V_{\bar{t}}^{\infty} \quad \Leftrightarrow \quad \sum_{\bar{t}}^{T} \rho^{t} U\left(C_{t}\right)>\sum_{\bar{t}}^{\infty} \rho^{t} U\left(P_{t}\right) \\
& V_{\bar{t}}^{T}>V_{\bar{t}}^{D} \quad \Leftrightarrow \quad \sum_{0}^{\infty} \rho^{t} U\left(D_{\bar{t}+t}\right)>0 .
\end{aligned}
$$

Obviously the latter condition is always fulfilled as long as there are any repercussions from defecting. From (8) it follows that if not committing to the attack was optimal at $t_{0}$, it will still be optimal at $\bar{t}$. As the decision at $t_{0}$ against the attack implied $V_{0}^{T}>V_{0}^{\infty}$ and we know that $V_{0}^{\infty}>V_{\bar{t}}^{\infty}$, it follows straightforwardly that the initial decision is time-consistent. If, however, the agent decided to commit the attack in $t_{0}$ (i.e. $V_{0}^{T}<V_{0}^{\infty}$ ) but not to defect (i.e. $V_{0}^{\infty}>V_{0}^{D}$ ), he might regret this decision later if $V_{\bar{t}}^{\infty}<V_{\bar{t}}^{T}$. Nevertheless, he will still carry out the attack, as he already determined at $t_{0}$ that defecting is suboptimal for him and $V_{0}^{\infty}-V_{0}^{D}=V_{\bar{t}}^{\infty}-V_{\bar{t}}^{D}>0$ holds.

So, we have seen that under constant discounting decisions are always time-consistent. Yet, when observing last minute defection in reality, this result does not seem entirely convincing. It can hardly account for cases in which a terrorist lets himself being rigged with the bomb and then does not pull the trigger. We will show, however, that this type of time-inconsistent behavior can be explained when giving up the assumption of constant discount rates.

\section{Optimal decisions under hyperbolic discounting}

Standard economic theory assumes - as we have done so far - that the rate at which individuals discount the future is constant over time. This assumption is fairly popular in dynamic economic theory as it not only facilitates the analysis but, as confirmed above, also results in timeconsistent decisions. Empirical studies have, however, shown (see Ainslie 1992, Laibson et al. 1998) that individuals regularly apply lower discount rates to events in the distant future compared to events which are closer in time. ${ }^{14}$ Under this type of discounting, also referred

\footnotetext{
${ }^{13}$ To be better able to compare (5) and (8), resp. (7) and (9), we discounted the present value of utility at $t=\bar{t}$ to $t=0$, i.e.$$
\sum_{0}^{T-\bar{t}} \rho^{t} U\left(C_{\bar{t}+t}\right)>\sum_{0}^{\infty} \rho^{t} U\left(P_{\bar{t}+t}\right) \Leftrightarrow \rho^{\bar{t}} \sum_{0}^{T-\bar{t}} \rho^{t} U\left(C_{\bar{t}+t}\right)>\rho^{\bar{t}} \sum_{0}^{\infty} \rho^{t} U\left(P_{\bar{t}+t}\right) \Leftrightarrow \sum_{\bar{t}}^{T} \rho^{t} U\left(C_{t}\right)>\sum_{\bar{t}}^{\infty} \rho^{t} U\left(P_{t}\right)
$$

and

$$
\sum_{0}^{\infty} \rho^{t} U\left(D_{\bar{t}+t}\right)>0 \Leftrightarrow \rho^{\bar{t}} \sum_{0}^{\infty} \rho^{t} U\left(D_{\bar{t}+t}\right)>0 \Leftrightarrow \sum_{\bar{t}}^{\infty} \rho^{t} U\left(D_{t}\right)>0 .
$$

The same holds for the derivation of (15) and (17).

${ }^{14} \mathrm{~A}$ typical example for this kind of behavior is the following: An agent who can choose between a gift of 10 Euro today or 10.50 Euro tomorrow chooses 10 Euro today. Given the choice, however, between 10 Euro in 365
} 
to as hyperbolic discounting, decisions are not necessarily time-consistent anymore. As Ainslie (1991) puts it, hyperbolic preferences can constitute "a major obstacle to rational planning[, as] any plan requiring a prolonged course of action will fail unless the person can arrange consistent motivation for or binding commitment to it" (Ainslie 1991: 334).

Several forms of hyperbolic discounting have been proposed in the literature. We employ one of the simplest notions (which has sometimes also been referred to as quasi-hyperbolic discounting, see Harris/Laibson 2001) since it simplifies the exposition but suffices to make our point. Compared to the previous section, quasi-hyperbolic discounting modifies the individual's discount factors from $\delta^{t}$ to $\beta \delta^{t}$ with $0<\beta \leq 1$. (1), (3) and (4) consequently read

$$
\begin{aligned}
V_{0}^{T h}\left(C_{t}\right) & =U\left(C_{0}\right)+\sum_{1}^{T} \beta \rho^{t} U\left(C_{t}\right) \\
V_{0}^{\infty h}(C, A, P) & =U\left(C_{0}\right)+U\left(A_{0}\right)+\sum_{1}^{\bar{t}} \beta \rho^{t}\left(U\left(C_{t}\right)+U\left(A_{t}\right)\right)+\sum_{\bar{t}}^{\infty} \beta \rho^{t} U\left(P_{t}\right) \\
V_{0}^{D h}(C, A, D) & =U\left(C_{0}\right)+U\left(A_{0}\right)+\sum_{1}^{\bar{t}} \beta \rho^{t}\left(U\left(C_{t}\right)+U\left(A_{t}\right)\right)+\sum_{\bar{t}}^{T} \beta \rho^{t} U\left(C_{t}\right)-\sum_{\bar{t}}^{\infty} \beta \rho^{t} U\left(D_{t}\right)
\end{aligned}
$$

where the additional superscript $h$ refers to the hyperbolic discounting scenario. Setting $\beta=1$ replicates the constant discounting case.

From (10) to (12) we see that multiplying by $\beta$ induces an decrease of the first period's discount factor from $\delta$ to $\beta \delta$. So, the relative weight of $U\left(C_{1}\right)$ to $U\left(C_{0}\right)$ is $\beta \delta$ while the relative weight of any other combination of $U\left(C_{t+1}\right)$ and $U\left(C_{t}\right), t \geq 1$, is $\delta$. Consequently, the agent's discount rate is initially higher than in the long run.

Now assume that it is optimal for an agent to truthfully announce at $t_{0}$ that he plans to carry out the attack, i.e. $V_{h}^{\infty}>V_{h}^{T}$ and $V_{h}^{\infty}>V_{h}^{D}$. In this case

$$
V_{0}^{\infty h}>V_{0}^{T h} \quad \Leftrightarrow \quad \frac{U\left(A_{0}\right)}{\beta}+\sum_{1}^{\bar{t}} \rho^{t} U\left(A_{t}\right)+\sum_{\bar{t}}^{\infty} \rho^{t} U\left(P_{t}\right)>\sum_{\bar{t}}^{T} \rho^{t} U\left(C_{t}\right)
$$

and

$$
V_{0}^{\infty h}>V_{0}^{D h} \quad \Leftrightarrow \quad \sum_{\bar{t}+1}^{\infty} \rho^{t}\left(U\left(P_{t}\right)+U\left(D_{t}\right)\right)-\sum_{\bar{t}+1}^{T} \rho^{t} U\left(C_{t}\right)>\rho^{\bar{t}}\left[U\left(C_{\bar{t}}\right)-U\left(D_{\bar{t}}\right)-U\left(P_{\bar{t}}\right)\right] .
$$

It can now be shown that the initial decision to carry out the attack might not be optimal when reevaluated at the time of the attack. At $\bar{t},(14)$ modifies to

$$
V_{\bar{t}}^{\infty h}>V_{\bar{t}}^{D h} \quad \Leftrightarrow \quad \sum_{\bar{t}+1}^{\infty} \rho^{t}\left(U\left(P_{t}\right)+U\left(D_{t}\right)\right)-\sum_{\bar{t}+1}^{T} \rho^{t} U\left(C_{t}\right)>\rho^{\bar{t}} \frac{\left[U\left(C_{\bar{t}}\right)-U\left(D_{\bar{t}}\right)-U\left(P_{\bar{t}}\right)\right]}{\beta} .
$$

days or 10.50 Euro in 366 days, he chooses the 10.50 Euro. While this behavior is not compatible with discounting at a constant rate, it is perfectly in line with hyperbolic discounting. Empirically, hyperbolic discounting is welldocumented and has, e.g., been employed in the analysis of addictive behavior (see O'Donoghue/Rabin 1999, Gruber/Koszegi 2001). 
As $\beta<1$ the RHS of (14) is smaller than the RHS of (15). Given that both conditions hold, the agent's initial decision will still be optimal. If, however, (14) holds while (15) does not hold, the agent will revise his decision and defect in spite of his former honest commitment to the attack. In this case hyperbolic discounting induces time-inconsistent behavior. (Please note that an agent who chose defection over carrying the attack out, never regrets this decision as in this case $\left.\operatorname{RHS}_{(15)}>\mathrm{RHS}_{(14)}>\operatorname{LHS}_{(14)}\right)$.

Let us now consider an agent who decides in $t_{0}$ not to become a suicide bomber which means that either $V_{0}^{T h}>V_{0}^{\infty h}>V_{0}^{D h}$ or $V_{0}^{T h}>V_{0}^{D h}>V_{0}^{\infty h}$. Rewriting (13), the former ranking implies

$$
V_{0}^{T h}>V_{0}^{\infty h} \quad \Leftrightarrow \quad \sum_{\bar{t}+1}^{T} \rho^{t} U\left(C_{t}\right)-\sum_{\bar{t}+1}^{\infty} \rho^{t} U\left(P_{t}\right)>\rho^{\bar{t}}\left[U\left(P_{\bar{t}}\right)-U\left(C_{\bar{t}}\right)\right]+\frac{U\left(A_{0}\right)}{\beta}+\sum_{1}^{\bar{t}} \rho^{t} U\left(A_{t}\right)
$$

while for the initial decision to still be optimal at $t=\bar{t}$

$$
V_{\bar{t}}^{T h}>V_{\bar{t}}^{\infty h} \quad \Leftrightarrow \quad \sum_{\bar{t}+1}^{T} \rho^{t} U\left(C_{t}\right)-\sum_{\bar{t}+1}^{\infty} \rho^{t} U\left(P_{t}\right)>\rho^{\bar{t}} \frac{\left[U\left(P_{\bar{t}}\right)-U\left(C_{\bar{t}}\right)\right]}{\beta}
$$

has to hold. Consequently, if $\mathrm{RHS}_{(17)}$ exceeds $\mathrm{RHS}_{(16)}$, the agent might regret that he committed against the attack. He can, however, not act time-inconsistently in this case. This would require to carry out the attack immediately and without any planning which we assumed to be impossible. Yet, even if the agent got another chance to commit to an attack at $2 \bar{t}$, he would again decide against the attack (given his utility profile remains the same) - although he just regretted his decision.

Finally, an agent who initially decided in favor of defection compared to non-involvement will always regret this decision at the time of the attack, as his additional utility from defecting is negative. ${ }^{15}$ Yet, as he already announced that he would commit the attack, non-involvement is not an option anymore. On the other hand, as we have seen above, it can never be optimal for a terrorist to switch from a defecting to a carrying-out strategy at $\bar{t}$. So, an agent who decided to defect in $t_{0}$ will always act time-consistently.

\section{$5 \quad$ Perception and manipulation of costs and benefits}

Following the line of reasoning above, one should expect a number of potential suicide attackers to refrain from the attack they originally agreed to. A look at the empirical data shows that indeed a few incidents have been reported in which terrorists changed their mind, sometimes in the virtually last second:

\footnotetext{
${ }^{15}$ Vice versa, an agent who initially chose non-involvement over defecting will never regret it at $\bar{t}$.
} 
- In November 2008 gunmen attacked several targets in Mumbai. One of the gunmen was captured and in the subsequent interrogations he provided information to the police. He reported that he was ordered to kill until the last breath (Siddique 2008). Yet, instead he pretended to be dead in order to survive.

- In January 2008 two terrorists strapped with explosives stormed a five-star hotel in Kabul firing automatic rifles. While one of these men detonated his bomb, the second attacker finally took off his bomb vest and hid (Fairweather 2008).

- In March 2004, Hussam Bilal Abdu from Nablus was arrested carrying an explosive belt (see also Section 2). He was judged to be "a bit of a loser, a messed-up adolescent in search of respect and fame among his peers" (Kiley 2004). Yet, when he was spotted by Israeli soldiers he complained that he does not want to die.

The question arises, why these incidents are not reported more often. Of course, it lies in the nature of the subject that data on this kind of behavior is rather scarce, yet it is also conceivable that there exist forces which prevent the potential suicide attacker from reversing his decision. These forces might be external in the sense that events or actions taken by people around the terrorist make him more unlikely to defect. Besides these external forces, the power of internal mechanisms should, however, not be underestimated. With internal mechanisms we mean selfenforcing processes that can, e.g., be caused by the desire to reduce cognitive dissonance or anxiety in the face of death.

\subsection{External manipulation forces}

How an agent perceives the costs and benefits of an attack depends to a large extend on his environment - ex ante as well as ex post of his decision. Terrorists' peer groups, terrorist organizations as well as entities countering terrorism employ a variety of different manipulation methods in order to convince a terrorist of the attack and keep him from defecting.

External manipulation by a terrorist organization could, e.g., include to raise the threat level associated with defection, $U\left(D_{t}\right)$. In the extreme, the threat could be made to kill the agent for his defection. In this case, he would not live to enjoy any private utility after defecting and even an infinitesimally small positive posthumous utility, $U\left(P_{t}\right)$, would be sufficient to make him commit the attack. A second option would be to increase posthumous utility, $U\left(P_{t}\right)$, by promises to the assassins' family and by raising the expectation of heavenly joys. ${ }^{16}$

Extremist organizations can furthermore manipulate their members' beliefs by keeping them in company only of others who share the desired beliefs (Hardin 2002). In the case of terrorists,

\footnotetext{
${ }^{16}$ Please note that it cannot be effective for a terrorist organization, which strives to prevent defection, to increase, $U\left(A_{t}\right)$. As a higher $U\left(A_{t}\right)$ not only increases the pay-off from the attack but also the pay-off from defection, it does not render defection less likely.
} 
isolation reduces the access to balanced information in favor of information that emphasizes positive effects of the attack and thereby promotes the organizations goals. ${ }^{17}$ The terrorist starts to perceive people outside his group as hostile which reduces the negative utility associated with killing or hurting them and thereby raises $U\left(P_{t}\right)$. Restricting access to information might also make the individual perceive that extreme violence is indeed the only effective way to promote the interests of his peer group. In addition, isolation in the group makes the impact of positive announcement effects, $U\left(A_{t}\right)$, more pronounced.

Summing up, terrorist organization's manipulation aims to affect all utility components related to the attack, i.e. it strives to rise announcement, posthumous as well as defection effects. Employing these tactics ex ante helps to tip the scale in favor of the terrorist attack even if agents are rational. Artificially creating imperfect information by denying access to comprehensive information and only allowing for biased or false information prevents the agent to attain his first-best optimum. He maximizes his utility under the information restriction and is left with the second-best. While he might have decided against a suicide attack in the first-best world, he might find it optimal in the second-best. To make it optimal for him to stick to this decision it is vital for the terrorist organization to keep up isolation in order to prevent the agent from re-evaluating the attack based on new information.

\subsection{Internal manipulation mechanisms}

Internal - in contrast to external - manipulation mechanisms and their role for decision processes of suicide attackers have to far rarely (an exception to the rule is Pittel/Rübbelke 2010) been considered by the economics' literature of terrorism. Yet, as we have seen, the decision to become a terrorist depends to a large extend on non-material utility components whose perception and evaluation seem to be even more susceptible to manipulation than preferences for material goods. This papers aims to close the existing gap in the literature by demonstrating the importance of internal mechanisms for not only the decision to become a suicide attacker, but also for the predicted time-inconsistency of this decision under realistic discounting assumptions.

In the following we focus on two aspects of the interaction between psychological and eco-

\footnotetext{
${ }^{17}$ Isolation efforts of this type can be found throughout history and as early as in the Assassins or IsmailisNizari period (1090-1275). The Assassins seized several scattered and impregnable mountain fortresses as retreat centres for their movement (see also Rapoport 1984). Comtemporary examples include Al Qaeda who encourages the training of its supporters in hidden military camps that "generate both the common collective identity and the shared tactics and repertoires that have informed the transnational cells" (Leheny 2005: 100). Hegghammer (2006: 46) stresses the crucial role of training camps in "violence acculturization, indoctrination, training and relations-building." Aum Shinrikyo who committed the Tokyo sarin attack in 1995 constructed nuclear shelters and communes where its members were separated from their families and children received no formal schooling (Pittel/Rübbelke 2006).
} 
nomic sphere: cognitive dissonance and mortality salience. ${ }^{18}$

\section{Cognitive dissonance}

Cognitive dissonance arises when two implications of an action have opposing effects (Festinger 1957). This dissonance creates a tension within an individual's mind that "gives rise to pressures to reduce or eliminate the dissonance" (Festinger 1957: 18), i.e. agents will form their beliefs and manipulate their perception of reality in order to reduce the tension. According to Dickens (1986), psychological studies suggest that agents systematically alter their beliefs to convince themselves that their decisions are correct and thereby reduce their 'psychic costs' (Cameron 1988). They will, for example, select their sources of information in favor of those sources that confirm their desired beliefs, respectively those beliefs that support decisions already taken (Akerlof/Dickens 1982). ${ }^{19}$ Suicide attacks naturally induce cognitive dissonance. On the one hand, they are associated with strong negative (dissonant) cognitions as not only the lives of others but especially one's own life is lost. On the other hand positive (consonant) cognitions arise from the feeling that one serves the goals of his peer group, attains glory and perhaps also leaves one's family better off. Maikovich (2005: 377) argues that "what differentiates the few who do become terrorists from the majority who do not is often the ability to reduce this cognitive dissonance".

The need to reduce cognitive dissonance arises mainly after the decision to become a suicide bomber has been made, although ex ante manipulation is also conceivable. In the latter case an agent manipulates his cognitions to strengthen those beliefs which are in favor of the preferred outcome. Jonas et al. (2003) stress that a confirmation bias is not restricted to situations in which a final decision has already been made. They argue that "a similar bias arises after preliminary decisions (preference judgments) if the decision maker feels committed to the preferred alternative" (Jonas et al. 2003: 1183). Nevertheless, ex ante manipulation only serves to justify a decision which would be preferred anyway. So, in spite of ex ante manipulation, the agent takes the decision that maximizes his welfare.

What about the situation after the decision? Cognitive dissonance in the form of costs and benefits of the decision are still present and the agent will strive to mitigate the dissonance in order to experience a higher level of utility. Once agreed to the suicide attack, he will search for information justifying his decision, thus creating a confirmation bias (see e.g Jonas et al. 2003 and references within). He might even choose not to be exposed to different views and seek the

\footnotetext{
${ }^{18}$ For a more comprehensive review of psychological approaches to terrorism see Victoroff (2005). 
seclusion offered by terrorist groups. ${ }^{20}$

In case future costs and benefits are discounted at a constant rate, this ex-post self-manipulation has no effect except for confirming decisions already made. In case of hyperbolic discounting, however, it might solve the time-inconsistency problem.

Recall that time-inconsistency arises when the discrepancy between short- and long-run discounting renders a different decision optimal at the time of the attack than at the time of the initial decision. For the attack to be optimal at $t=0,(14)$ has to hold, while (15), i.e.

$$
\sum_{\bar{t}+1}^{\infty} \rho^{t}\left(U\left(P_{t}\right)+U\left(D_{t}\right)\right)-\sum_{\bar{t}+1}^{T} \rho^{t} U\left(C_{t}\right)>\rho^{\bar{t}} \frac{\left[U\left(C_{\bar{t}}\right)-U\left(D_{\bar{t}}\right)-U\left(P_{\bar{t}}\right)\right]}{\beta} .
$$

has to hold at the time of the attack. Time-inconsistency arises if (14) but not (15) holds. Aversion of cognitive dissonance makes time-inconsistency less likely to arise, as the agent perceives $U\left(P_{t}\right)$ and $U\left(D_{t}\right)$, the posthumous and defection effects, stronger than before while he downplays the utility of foregone consumption, $U\left(C_{t}\right)$ ). This implies that the LHS of (15) rises while the RHS falls. An agent who might regret his decision when cognitive dissonance is not taken into account, might stick to it due to self-manipulation.

So, taking cognitive dissonance mitigating processes into account might explain why - although experiments support the hyperbolic discounting hypothesis - not many terrorists seem to rescind their commitment to a suicide attack. Of course, the described effects of cognitive dissonance do not arise exclusively in the extreme case of suicide attacks, they are present whenever a decision creates opposing cognitions. The case of suicide attacks is, however, special as it involves to come to terms with one's own death, i.e. it increases mortality salience which in turn affects the utility agents derive from suicide attacks.

\section{Mortality Salience}

The psychological effects caused by the fear that follows from mortality salience are addressed by terror management theory (TMT). ${ }^{21}$ According to TMT, becoming aware of death fosters the need to defend one's worldview and increases negative reactions to those who threaten this view. ${ }^{22}$ It is argued that the cultural worldview provides protection from the 'existential' fear of

\footnotetext{
${ }^{20}$ For overviews of empirical studies that provide evidence for a confirmation bias see Frey (1986) and Frey et al. (1996).

${ }^{21}$ TMT builds on the theoretical works of Greenberg et al. (e.g. Greenberg et al. 1986, 1997). It was tested and confirmed by a large number of empirical studies, for an overview see, e.g., Solomon et al. (2004). In spite of its name, terror management theory is a psychological concept which roots are unrelated to terrorism theory, but whose implications can be very relevant to explaining the time-consistency of decisions to commit terrorist attacks.

22 "The cultural worldview is defined as a set of beliefs about the nature of reality shared by groups of individuals
} 
death. Consequently, an increase in the awareness of death "intensifies the desire to pursue faith in the individual's cultural worldview, its meaning, order, and stability" (Jonas et al. 2003: 1181). The increased importance of an unchallenged worldview also increases the desire for cognitive consistency such that the confirmation bias in the selection of information becomes more pronounced. Reducing information that calls one's worldview into question, has been shown to increase one's self-esteem and thereby reduce anxieties (see Jonas et al. 2003).

In terms of utility, mortality salience increases the benefits an individual derives from abetting the goals of his peer group by committing a suicide attack. It furthermore reduces the feeling of guilt towards victims of the attack as it implicitly justifies decisions to defend one's worldview with drastic means. Both effects raise the utility which a terrorist derives from the posthumous effects, $U\left(P_{t}\right)$. Depending on whether mortality salience increases mainly before or after $t_{0}$, its effects differ. If considering the attack already rises mortality salience, a commitment to the attack becomes more likely while the potential for time-inconsistency remains unaffected. If, however, mortality salience rises chiefly after the agent agreed to the attack, it makes time-inconsistent behavior less likely as $U\left(P_{t}\right)$ in (15) is perceived to be higher than $U\left(P_{t}\right)$ in (14). It seems fair to assume that both, contemplation of a suicide attack (at $t \leq 0$ ) and the potential certainty of death (after $t>0$ ), affect mortality salience.

So far, we have argued that considering a suicide attack increases mortality salience. Yet, mortality salience might also raise the individual's readiness to commit a suicide attack. Routledge/Arndt (2008) show that awareness of death raises the willingness to self-sacrifice in order to secure some kind of religious or symbolic immortality. ${ }^{23}$ Contemplating a suicide attack consequently bears signs of a self-fulfilling prophecy: thinking about an attack raises mortality salience and mortality salience raises the willingness to commit an attack. Speaking in terms of costs and benefits, mortality salience raises the utility individuals derive from the expectation of immortality, i.e. it increases the non-altruistic components of $U\left(P_{t}\right)$.

\section{$6 \quad$ Policy implications}

As research in the last decades has shown, policy advise in the face of terrorism and especially suicide terrorism is difficult. Seemingly straightforward means to combat terrorism like providing education or reducing poverty have in many cases been unsuccessful as "suicide bombers are at least as likely to come from economically advantaged families and have a relatively high level of education as to come from the ranks of the economically disadvantaged and uneducated." (see

that provides meaning, order, permanence, stability, and the promise of literal and/or symbolic immortality to those who live up to the standards of value set by the worldview." (Jonas et al. 2003: 1182).

${ }^{23}$ In their paper, Routledge and Arndt confirm by experiments that English citizen's willingness to die for their country rises with mortality salience. 
Krueger/Maleckova 2003: 141). ${ }^{24}$

Our paper supports the view that suicide attackers are driven to a large extend by nonmonetary motivations. So, policies that battle terrorism should target especially non-monetary motives for suicide attacks. In the following we will concentrate on some counter-terrorism measures that seem promising in the light of the preceding discussion. They can be classified along two lines: First, to provide alternatives to suicide attackers, and, second, to combat the information bias.

Providing alternatives can and has to encompass a variety of issues since, as we have seen above, better living standards alone will not solve the problem. Krueger and Maleckova (2003) stress that terrorism should rather be seen as an answer to political conditions and feelings of indignity and frustration. Consequently, providing alternatives should start with battling these conditions and feelings. Section 2 showed that terrorism is often born from desperation and the conviction that committing a terrorist act is the only means left to overcome this despair. Policies should therefore try and break-up societal structures that foster no-way-out situations - as was the case for Idris, the divorced Palestinian suicide attacker. Also, the importance of dialogue between parties involved in terrorism causing conflicts becomes clear in this context as it constitutes an important means to reduce no-way-out feelings. In terms of the above introduced benefits from terrorism, no-way-out situations tend to raise $U\left(A_{t}\right)$ and $U\left(P_{t}\right)$ and lower the utility attached to a life without the attack. In the face of no other option, committing the attack becomes more important and is easier to justify. Consequently, a change for the better resulting from the attack is valued higher and so are the terrorists who carry out the attack.

Alternatives to terrorist organizations should also be provided in the context of social services as health care and education. As elaborated before, organizations like Hamas and IRA provide social services and thereby induce consonant cognitions which render services to the terrorist organization more valuable (i.e. in our model: increase of $U\left(A_{t}\right)$ and $U\left(P_{t}\right)$ ). Policy maker should strive to reduce these consonant cognitions by either offering alternative services or supporting moderate groups in providing them.

One policy program that takes the above aspects into account was set up in, e.g., Saudi Arabia. The program al-Munasahah provides psychological and sociological counseling as well as religious dialogue in order to encourage imprisoned terrorist supporters "to renounce their radical ideology" (Ansary 2008: 118). By assisting prisoners and their families with education, health care and finding employment, the program aims to show ways out of desperation and to provide alternative life perspectives to terrorists. ${ }^{25}$

\footnotetext{
${ }^{24}$ Schellenbach (2006) furthermore argues that raising income through, e.g., foreign aid and thereby "increasing opportunity costs of terrorism may be understood as an indirect reward for terrorist activity" in the long run (Schellenbach 2006: 305).

${ }^{25}$ Although there have been reports on participants of this program returning to terrorist groups, the all-over
} 
Especially relevant in the context of suicide attacks is also to decrease mortality salience. Living under conditions that are bound to increase mortality salience fosters suicide attacks as corroborated by the statement of the second female suicide attacker Abu Aysheh (see Section 2). Also, counter-terrorism policies should try to provide alternatives to attain immortality. Routledge/Arndt (2008) show that the willingness to sacrifice oneself in the face of mortality salience decreases when alternative ways to achieve immortality are available. In terms of our model, the posthumous utility from the attack would decrease and render a decision in favor of the attack less likely.

A second policy recommendation following from this paper would be to decrease the information bias to which potential suicide attackers are either subjected by others or subject themselves. Regarding the external information bias, policy makers should attempt to make it harder for terrorist organizations to isolate their members and thereby restrict their access to information. One option would be to battle the information bias present in the mass media of some countries. According to Haddad/Khashan (2002: 825), "[t]he mass media and other agents of socialization in Arab and Muslim lands never cease telling their publics that the Western-led United States is largely responsible for their debacle." Increasing the access to and number of news providers could be one way to improve the dissemination of less-biased information (see Faria/Arce M. 2005).

Attempts to fight internal dissonance-reducing information biases should follow the same lines. Subjecting agents to more unbiased information makes it harder for them to ignore dissonance causing information. The Quilliam Foundation, e.g. - a self-proclaimed counterextremism think-tank (Quilliam Foundation 2009) - focuses specifically on fostering moderate islam and thereby tries to provide an alternative world view based on muslim tradition (The Guardian 2008).

Increasing access to information is, however, not the only means to combat terrorism by increasing cognitive dissonance. Policies could address any (self-) delusional strategies that aim at either increasing consonant or reducing dissonant cognitions - or their respective importance.

Maikovich (2005) presents a list of worldview relevant conditions which contribute to reducing the cognitive dissonance caused by the decision to become a terrorist. Among these are a lack of legal means to achieve change, a 'good vs evil view' of the world and the perception of society as illegitimate and unjust - to name a few (Maikovich 2005: 380). Policies that succeed in ameliorating any part of this 'black-and-white' perception of the world will contribute to fighting terrorism.

performance of the program seems to be good: a program official announced that "only nine of the 700 released, following the rejection of radical and deviant views, have returned to their previous ideologies" (Ansary 2008: 121). 
Beyond the worldview of terrorists, it is also the extent of media attention that determines the information bias and defines the benefits of terrorism. More media attention implies more success in drawing attention to one's cause, but also means more fame for the attacker - both of which increase the posthumous utility attainable from an attack. In order to mitigate the publicity of terrorist action, it is important to derogate the symbiotic relationship between terrorism and the media. As Rohner/Frey (2007: 142) point out: "There is a common-interestgame, whereby both the media and terrorists benefit from terrorist incidents and where both parties adjust their actions according to the actions of the other player." Among the policy recommendations Rohner/Frey (2007: 142) make, are the avoidance of attributing terrorist attacks to particular groups and the subsidization of high quality journalism. In this context, broadcasting videotapes in which the terrorist quasi officially announce their attack is of special importance as these videotapes not only increase the fame of the attacker but may also serve as a commitment device designed to reduce defecting.

\section{Conclusions}

This paper aimed at providing some theoretical rationale as to why the decision to become a suicide bomber might be rational from an economist's point of view. It argued that although a terrorist forfeits his future utility from consumption by committing an attack, this loss might be overcompensated by the utility he derives from the attack. Non-monetary benefits from pride, an increased social status of the attacker and his family, immortality and possibly even monetary benefits the family receives posthumously from the terrorist organization might well outweigh the foregone utility from consumption. We demonstrated the different types of motivation of suicide bombers as well as the diversity of their profiles by analyzing some individual cases.

We then derived conditions under which a rational agent might decide to become a suicide attacker - or to announce the attack and defect later. It was shown under which circumstances the decision to commit a suicide attack can be time-inconsistent and what mechanisms might prevent time-inconsistency. Integrating the psychological concepts of cognitive dissonance and terror management theory into our economic analysis, we demonstrated why - although predicted by standard economic theory - defection is a phenomenon rarely observed. As individuals try to reduce the cognitive dissonance associated with the decision to commit a suicide attack, they select biased information that supports their decision to commit an attack. This reduces the perceived costs and increases the perceived benefits from an attack, making defection less likely. Terror management theory argues that a higher awareness of death increases the need to reduce cognitive dissonance and thereby raises the perceived benefits of terrorism even further. As desperation and no-way-out situations foster the awareness of death, it is straightforward 
that a higher readiness for self-sacrifice can be observed in many crisis regions. We argue that once the decision to become a suicide bomber is made, the certainty of death even fortifies the terror management effects.

We closed by presenting some policy implications. In the light of our analysis, policies that focus on material well-being seem less promising than policies that address the non-monetary benefits of suicide attacks. The paper concentrated on two policy strategies: offering alternatives (with respect to the aims of terrorism as well as the means to attain them) and reducing the information bias (with respect to the availability as well as the access to information).

Our analysis focused largely on the drivers of suicide attacks in the sphere of the individual attacker, although we also considered influence mechanisms employed by the terrorist organization or leaders. In order to get a more comprehensive view, future analysis should encompass the sphere and motives of terrorist leaders. Developing policies that address these motives may open up further options to counter suicide-terrorism.

\section{References}

Ainslie, G.W. (1991), Derivation of "Rational" Economic Behavior from Hyperbolic Discount Curves, The American Economic Review 81, Papers and Proceedings of 103rd Annual Meeting of the American Economic Association, 334-340.

Ainslie, G.W. (1992), Picoeconomics, Cambridge University Press, Cambridge.

Ainslie, G.W./Haslam, N. (1992), Hyperbolic Discounting, in: Loewenstein, G./Elster, J. (eds.), Choice over time, New York: Sage Foundation, 57-92.

Akerlof, G.A. and Dickens, W.T. (1982), The Economic Consequences of Cognitive Dissonance, American Economic Review 72, 307-319.

Alvanou, M. (2007), Palestinian Women Suicide Bombers: The Interplaying Effects of Islam, Nationalism and Honour Culture, Strategic Research and Policy Center, National Defense College, IDF, Working Paper No. 3 (Tel Aviv).

Ansary, A.F. (2008), Combating Extremism: A Brief Overview of Saudi Arabia's Approach, Middle East Policy 15, 111-142.

Azam, J.-P. (2005), Suicide-bombing as inter-generational investment, Public Choice 122, 177-198.

Bennet, J. (2002), Arab Woman's Path to Unlikely 'Martyrdom', New York Times, January 31.

Berman, E./Laitin, D.D. (2005), Hard Targets: Theory and Evidence on Suicide Attacks, mimeo.

Bueno de Mesquita, E. (2005), Conciliation, Counterterrorism, and Terrorist Violence, International Organization 59, 145-176.

Cameron, S. (1988), The Economics of Crime Deterrence: A Survey of Theory and Evidence, Kyklos 41, 301-323.

Caplan, B. (2006), Terrorism: The Relevance of the Rational Choice Model, Public Choice 128, 91-107. 
CFR - Council on Foreign Relations (2009), http://www.cfr.org/publication/8968.

Dickens, W.T. (1986), Crime and Punishment Again: The Economic Approach with a Psychological Twist, Journal of Public Economics 30, 97-107.

Fairweather, J. (2008), The Failed Suicide Bomber Who Changed the War on Terror in Afghanistan, Telegraph, November 13.

Faria, J.R./Arce M., D.G. (2005), Terror Support and Recruitment, Defence and Peace Economics 16, 263-273.

Festinger, L. (1957), A Theory of Cognitive Dissonance, Row, Peterson and Company (Evanston).

Frey, D. (1986), Recent research on selective exposure to information, in: Berkowitz, L. (ed.), Advances in experimental social psychology 19, 41-80.

Frey, D./Schulz-Hardt, S./Stahlberg, D. (1996), Information seeking among individuals and groups and possible consequences for decision making in business and politics, in:Witte, E.H./Davis, J.H. (eds.), Understanding Group Behavior - Small Group Processes and Interpersonal Relations, Mahwah/NJ: Lawrence Erlbaum Associates, 211-225.

Greenberg, J. (2002), Portrait of an Angry Young Arab Woman, New York Times, March 1.

Greenberg, J./Psyszczynski, T./Solomon, S. (1986), The causes and consequences of a need of selfesteem: A terror management theory, in: Baumeister, R.F. (ed.), Public Self and Private Self, New York: Springer, 189-212.

Greenberg, J./Solomon, S./Psyszczynski, T. (1997), The causes and consequences of a need of selfesteem and social behavior: Empirical assessments and conceptual refinements, in: Zanna, M.P. (ed.), Advances in experimental social psychology, New York: Academic, 61-139.

Gruber, J./Koszegi, B. (2001), Is Addiction 'Rational': Theory and Evidence, The Quarterly Journal of Economics 116, 1261-1303.

Haddad, S./Khashan, H. (2002), Islam and Terrorism: Lebanese Muslim Views on September 11, Journal of Conflict Resolution 46, 812-828.

Hardin, R. (2002), The Crippled Epistemology of Extremism, in: Breton, A./Galeotti, G./Salmon, P./Wintrobe, R., Political Extremism and Rationality, Cambridge: Cambridge University Press.

Harel, A./Regular, A. (2004), IDF Apprehends 14-year-old suicide bomber, Haaretz, March 25.

Harris, C./Laibson, D. (2001), Dynamic choices of hyperbolic consumers, Econometrica 69, 935-957.

Hassan, N. (2001), An Arsenal of Believers, The New Yorker, November 19, pp. 36-41.

Hegghammer, T. (2006), Terror Recruitment and Radicalization in Saudi Arabia, Middle East Policy $13,39-60$.

Hilsenrath, P. (2005), Health policy as counter-terrorism: Health-Services and the Palestinians, Defence and Peace Economics 16, 365-374.

Jonas, E./Greenberg, J./Frey, D. (2003), Connecting Terror Management and Dissonance Theory: Evidence That Mortality Salience Increases the Preference for Supporting Information After Decisions, Personality and Social Psychology Bulletin 29, 1181-1189. 
Keller, B. (2002), Springtime for Saddam, The New York Times, April 6, p. A15.

Kiley, S. (2004), In a War Without Heroes, This Boy Was no Martyr, Observer, March 28.

Krueger, A.B./Maleckova, J. (2003), Education, Poverty and Terrorism: There a Causal Connection?, Journal of Economic Perspectives 17, 119-144.

Laibson D. I./Reperto A./Tobacman J. (1998), Self Control and Saving for Retirement, Brookings Papers on Economic Activity, I.

Laquer, W. (1990), Reflections on the eradication of terrorism, in: Kegley, C. Jr (ed.), International terrorism, New York: St. Martins Press.

Lee, D.R./Sandler, T. (1989), On the optimal retaliation against terrorists: The paid-rider option, Public Choice 61, 141-152.

Leheny, D. (2005), Terrorism, Social Movements, and International Security: How Al Qaeda Affects Southeast Asia, Japanese Journal of Political Science 6, 87-109.

Loewenstein, G./Elster, J. (1992), Choice over time, New York: Sage Foundation.

Maikovich, A.K. (2005), A New Understanding of Terrorism Using Cognitive Dissonance Principles, Journal for the Theory of Social Behaviour 35, 373-397.

McElroy, D. (2008), Mumbai Attacks: Surviving Attacker 'sold' to terrorists by father, Telegraph, December 2.

O'Donoghue, T./Rabin, M. (1999), Addiction and Self Control, in Jon Elster (ed.) Addiction: Entries and Exits, Russell Sage Foundation, 169-206.

Pape, R.A. (2003), The Strategic Logic of Suicide Terrorism, American Political Science Review 97, 343-361.

Pape, R.A. (2005), Dying to Win: The Strategic Logic of Suicide Terrorism, Random House.

Pittel, K./Rübbelke, D.T.G. (2006), What Directs a Terrorist?, Defence and Peace Economics 17, 311328.

Pittel, K./Rübbelke, D.T.G. (2010), Characteristics of Terrorism, forthcoming in: Braddon, D./Hartley, K., Handbook on the Economics of Conflict, Cheltenham: Edward Elgar.

Quilliam Foundation (2009), www.quilliamfoundation.org.

Rapoport, D.C. (1984), Fear and Trembling: Terrorism in Three Religious Traditions, The American Political Science Review 78, 658-677.

Rohner, D. and Frey, B.S. (2007), Blood and Ink! The Common-interest-game between Terrorists and the Media, Public Choice 133, 129-145.

Routledge, C./Arndt, J. (2008), Self-sacrifice as self-defence: Mortality salience increases efforts to affirm a symbolic immortal self at the expense of the physical self, European Journal of Social Psychology $38,531-541$.

Saloul, I. (2003), Martyrdom, Gender and Cultural Identity: The Cases of Four Female Palestinian Martyrs, Unpublished MA Thesis. University of Amsterdam. 
Schellenbach, J. (2006), Appeasing nihilists? Some economic thoughts on reducing terrorist activity, Public Choice 129, 301-313.

Schweitzer, Y. (2006), Introduction, in: Schweitzer, Y. (ed.), Female Suicide Bombers: Dying for Equality?, Memorandum No. 84, Jaffee Center for Strategic Studies, Tel Aviv University, Tel Aviv.

Siddique, H. (2008), 'We Were Told to Kill Until the Last Breath', Guardian, November 30.

Silke, A. (1998), Cheshire-cat logic: The recurring theme of terrorist abnormality in psychological research, Psychology, Crime \& Law, 4, 51-69.

Silke, A. (1999), Rebel's dilemma: The changing relationship between the IRA, Sinn Féin and paramilitary vigilantism in Northern Ireland, Terrorism and Political Violence 11, 55-93.

Solomon, S./Greenberg, J./Pyszczynski, T. (2004), The cultural animal: Twenty years of terror management theory and research. In Greenberg, J./Koole, S.L./Pyszczynski T. (eds.), Handbook of experimental existential psychology, New York: Guilford Press, 13-34.

The Guardian (2008), Ex-Islamists start moderate thinktank, March 1, 2008.

Victor, B. (2003), Army of Roses. Inside the World of Palestinian Suicide Bombers, London: Robinson.

Victoroff, J. (2005), The Mind of the Terrorist: A Review and Critique of Psychological Approaches, Journal of Conflict Resolution 49, 3-42.

Weatherston, D./Moran, J. (2003), Terrorism and Mental Illness: Is there a Relationship?, International Journal of Offender Therapy and Comparative Criminology, 47, 698-713.

Wintrobe, R. (2006), Extremism, Suicide Terror, and Authoritarianism, Public Choice 128, 169-195. 


\section{Working Papers of the Center of Economic Research at ETH Zurich}

(PDF-files of the Working Papers can be downloaded at www.cer.ethz.ch/research).

09/106 K. Pittel and D.T.G. Rübbelke

Decision Processes of a Suicide Bomber - Integrating Economics and Psychology

08/105 A. Ziegler, T. Busch and V.H. Hoffmann

Corporate Responses to Climate Change and Financial Performance: The Impact of Climate Policy

09/104 S. Valente

Endogenous Growth, Backstop Technology Adoption and Optimal Jumps

09/103 K. Pittel and D. Rübbelke

Characteristics of Terrorism

09/102 J. Daubanes

Taxation of Oil Products and GDP Dynamics of Oil-rich Countries

09/101 S. Valente

Accumulation Regimes in Dynastic Economies with Resource Dependence and Habit Formation

08/100 A. Ziegler

Disentangling Specific Subsets of Innovations: A Micro-Econometric Analysis of their Determinants

08/99 M. Bambi and A. Saïdi

Increasing Returns to Scale and Welfare: Ranking the Multiple Deterministic Equilibria

08/98 M. Bambi

Unifying time-to-build theory

08/97 H. Gersbach and R. Winkler

International Emission Permit Markets with Refunding

08/96 K. Pittel and L. Bretschger

Sectoral Heterogeneity, Resource Depletion, and Directed Technical Change: Theory and Policy

08/95 M. D. König, S. Battiston, M. Napoletano and F. Schweitzer

The Efficiency and Evolution of R\&D Networks

08/94 H. Gersbach and F. Mühe

Vote-Buying and Growth

08/93 H. Gersbach

Banking with Contingent Contracts, Macroeconomic Risks, and Banking Crises 
08/92 J. Daubanes

Optimal taxation of a monopolistic extractor: Are subsidies necessary?

08/91 R. Winkler

Optimal control of pollutants with delayed stock accumulation

08/90 S. Rausch and T. F. Rutherford

Computation of Equilibria in OLG Models with Many Heterogeneous Households

08/89 E. J. Balistreri, R. H. Hillberry and T. F. Rutherford

Structural Estimation and Solution of International TradeModels with Heterogeneous Firms

08/88 E. Mayer and O. Grimm

Countercyclical Taxation and Price Dispersion

08/87 L. Bretschger

Population growth and natural resource scarcity: long-run development under seemingly unfavourable conditions

08/86 M. J. Baker, C. N. Brunnschweiler, and E. H. Bulte

Did History Breed Inequality? Colonial Factor Endowments and Modern Income Distribution

08/85 U. von Arx and A. Ziegler

The Effect of CSR on Stock Performance: New Evidence for the USA and Europe

08/84 H. Gersbach and V. Hahn

Forward Guidance for Monetary Policy: Is It Desirable?

08/83 I. A. MacKenzie

On the Sequential Choice of Tradable Permit Allocations

08/82 I. A. MacKenzie, N. Hanley and T. Kornienko

A Permit Allocation Contest for a Tradable Pollution Permit Market

08/81 D. Schiess and R. Wehrli

The Calm Before the Storm? - Anticipating the Arrival of General Purpose Technologies

08/80 D. S. Damianov and J. G. Becker Auctions with Variable Supply: Uniform Price versus Discriminatory

08/79 H. Gersbach, M. T. Schneider and O. Schneller On the Design of Basic-Research Policy

08/78 C. N. Brunnschweiler and E. H. Bulte Natural Resources and Violent Conflict: Resource Abundance, Dependence and the Onset of Civil Wars

07/77 A. Schäfer, S. Valente

Habit Formation, Dynastic Altruism, and Population Dynamics 
07/76 R. Winkler

Why do ICDPs fail? The relationship between subsistence farming, poaching and ecotourism in wildlife and habitat conservation

07/75 S. Valente

International Status Seeking, Trade, and Growth Leadership

07/74 J. Durieu, H. Haller, N. Querou and P. Solal

Ordinal Games

07/73 V. Hahn

Information Acquisition by Price-Setters and Monetary Policy

07/72 H. Gersbach and H. Haller

Hierarchical Trade and Endogenous Price Distortions

07/71 C. Heinzel and R. Winkler

The Role of Environmental and Technology Policies in the Transition to a Lowcarbon Energy Industry

07/70 T. Fahrenberger and H. Gersbach

Minority Voting and Long-term Decisions

07/69 H. Gersbach and R. Winkler

On the Design of Global Refunding and Climate Change

07/68 S. Valente

Human Capital, Resource Constraints and Intergenerational Fairness

07/67 O. Grimm and S. Ried

Macroeconomic Policy in a Heterogeneous Monetary Union

07/66 O. Grimm

Fiscal Discipline and Stability under Currency Board Systems

07/65 M. T. Schneider

Knowledge Codification and Endogenous Growth

07/64 T. Fahrenberger and H. Gersbach

Legislative Process with Open Rules

07/63 U. von Arx and A. Schäfer

The Influence of Pension Funds on Corporate Governance

07/62 H. Gersbach

The Global Refunding System and Climate Change

06/61 C. N. Brunnschweiler and E. H. Bulte

The Resource Curse Revisited and Revised: A Tale of Paradoxes and Red Herrings

06/60 R. Winkler

Now or Never: Environmental Protection under Hyperbolic Discounting 